Doi:10.35414/akufemubid.486691

Araştırma Makalesi / Research Article

\title{
Sentinel-2A Uydu Görüntüsünde Nesne Tabanlı Sınıflandırma Yöntemi Kullanılarak Kıyı Habitatlarının Haritalanması
}

\author{
Ebru ERSOY ${ }^{*}$, K. Tulühan YILMAZ ${ }^{2}$, Birsen K. ATAK ${ }^{1}$, Derya Y. GÜLÇiN ${ }^{1}$ \\ ${ }^{1}$ Aydın Adnan Menderes Üniversitesi, Ziraat Fakültesi, Peyzaj Mimarlığı Bölümü, Aydın. \\ "Sorumlu yazar: Ebru ERSOY, e-posta: ebru.ersoy@adu.edu.tr, ORCID ID: https://orcid.org/0000-0002-2945-3885 \\ e-posta:birsenatak@adu.edu.tr, ORCID ID: https://orcid.org/0000-0003-4786-0801 \\ e-posta:derya.yazgi@adu.edu.tr, ORCIDID: https://orcid.org/0000-0001-7118-0174 \\ ${ }^{2}$ Çukurova Üniversitesi, Mimarlık Fakültesi, Peyzaj Mimarlığı Bölümü, Balcalı, Adana. \\ e-posta:tuluhan@cu.edu.tr, ORCID ID: https://orcid.org/0000-0003-2663-1583
}

Geliş Tarihi: 22.11.2018 Kabul Tarihi: 14.02.2019

\section{Anahtar kelimeler} Habitat haritası; Sentinel-2A; Nesne tabanlı sınıflandırma; e- Cognition

Öz

Bu çalışma ile Aydın ili sınırları içinde yer alan, Dilek Yarımadası-Büyük Menderes Deltası Milli Parkı, Bafa Gölü Tabiat Parkı, Azap Gölü ve Büyük Menderes Nehrinin oluşturduğu su ve sulak alan sisteminde planlama çalışmalarına altlık oluşturabilecek bir habitat haritasının oluşturulması amaçlanmıştır. Bu amaçla USGS EarthExplorer websitelerinden ücretsiz olarak temin edilen (11 Ağustos 2017 tarihli ve $10 \mathrm{~m}$ yersel çözünürlüklü) Sentinel-2A uydu görüntüsü veriseti kullanılmıştır (USGS, 2018). Ayrıca, sınıflandırmanın doğruluğunu arttırmak amacıyla NASA Earthdata websitesinden ücretsiz olarak temin edilen $30 \mathrm{~m}$ yersel çözünürlüklü ASTER Global DEM sayısal yükseklik modeli verisi (NASA Earthdata, 2018) ile Köy Hizmetleri Genel Müdürlüğü’nün hazırladığı toprak haritalarından yararlanılmıştır. Habitat haritası, arazi çalışmalarına dayalı vejetasyon analizi kayıtlarından elde edilen bulgular ışığında eCognition yazılımında nesne tabanlı sınıflandırma yöntemi kullanılarak hazırlanmıştır. Oluşturulan habitat haritasında 17 habitat sınıfı tanımlanmıştır. Çalışma alanında hakim habitat tipi; Tarla Tarımı'ndan oluşurken, su ve sulak alan sistemlerinin temelini oluşturan habitatlar ise çalışma alanının yaklaşık \%20'sini oluşturmaktadır. Sonuç olarak, yüksek çözünürlüklü uydu görüntüleri ile birlikte dijital yükseklik modeli ile vejetasyon birimleri ve farklı toprak özelliklerinin sınıflandırma sürecine dâhil edilmesiyle, peyzajın birçok fiziksel özelliğinin de dikkate alındığı, doğruluk oranı yüksek habitat haritalarının elde edilebileceği sonucuna varılmıştır.

\section{Coastal Habitat Mapping with Object Based Classification Method on the Sentinel-2A Satellite Imagery}

\begin{abstract}
In this study, it is aimed to create a habitat map that can form a base for planning studies in the water and wetland system formed by Dilek Peninsula-Büyük Menderes Delta National Park, Bafa Lake Nature Park, Azap Lake and Büyük Menderes River. For this purpose, the Sentinel-2A satellite image (dated 11 August 2017 and with a spatial resolution of $10 \mathrm{~m}$ ) that we obtained free of charge from the USGS Earth Explorer was used (USGS, 2018). In order to increase the accuracy of the habitat map, we have also used the ASTER Global DEM with a spatial resolution of $30 \mathrm{~m}$ which was obtaied from the NASA Earthdata website free of charge (NASA Earthdata, 2018) and the soil map created by the General Directorate of Rural Services. The habitat map was prepared using e-Cognition software and objectbased classification method in the light of the results obtained from the vegetation analysis records conducted during our field studies. In our habitat map, 17 habitat classes were defined. While the dominant habitat type in the study area consists of Arable land, the habitats that constitute the basis of water and wetland systems cover approximately $20 \%$ of the whole study area. As a result, it has been concluded that by incorporating different datastes, the digital elevation model, different soil characteristics and vegetation units together with the high resolution satellite images into the image classification process, many physical characteristics of a landscape are taken into consideration and high-accuracy habitat maps can be obtained.
\end{abstract}

Keywords

Habitat map; Sentinel-

2A; Object based

classification;

e-Cognition 
Şekil 1. Çalışma alanı
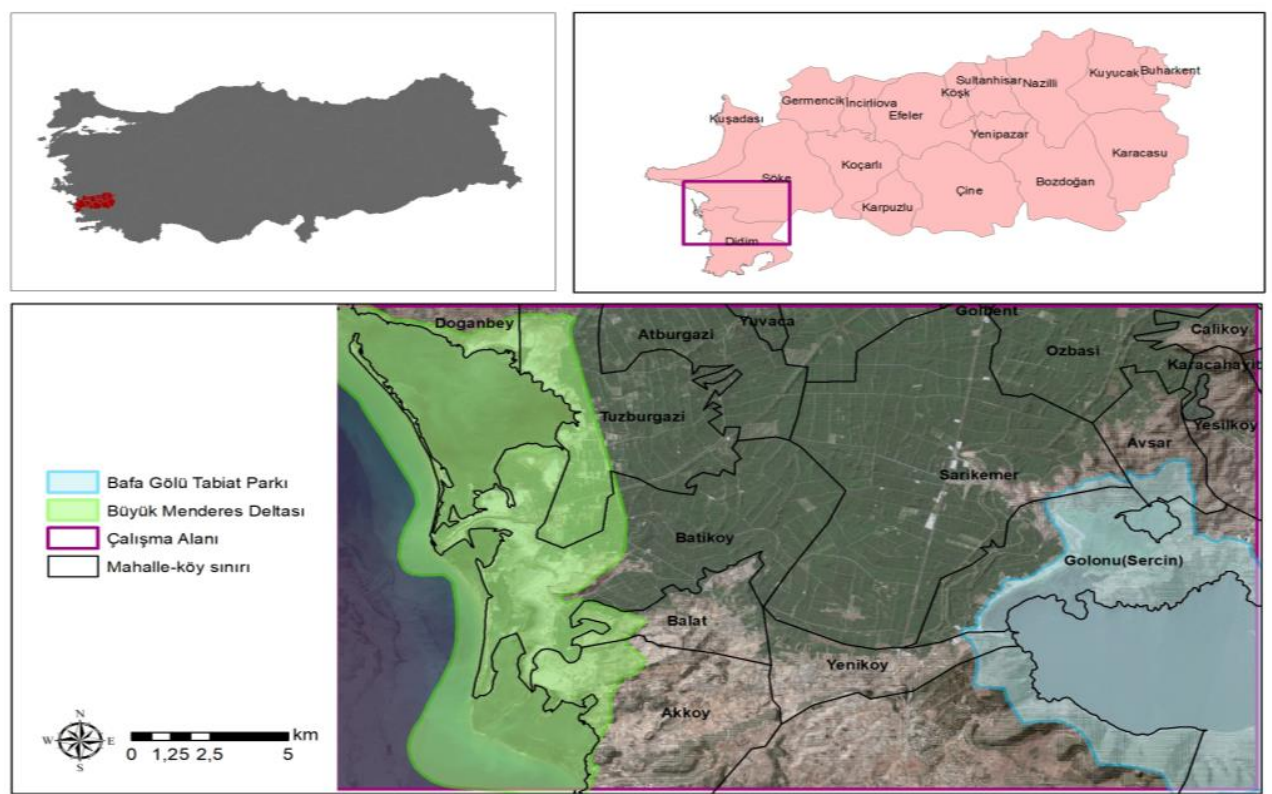

(C) Afyon Kocatepe Üniversitesi

\section{Giriş}

Yaklaşık olarak 1960'lı yıllarda başlayan sulak alanları koruma girişimleri, 1971 yılında İran'ın Ramsar kentinde imzalanan 'Özellikle Su Kuşları Yaşama Ortamı Olarak Uluslararası Öneme Sahip Sulak Alanların Korunması Sözleşmesi' (Ramsar Sözleşmesi 1971) ile beraber daha somut bir eylem biçimi olarak tüm dünyada ele alınmaya başlamıştır.

Ramsar Sözleşmesi'ne göre, sulak alanlar 'bataklıklar, turbalıklar, taşkın düzlükleri, nehirler, göller, tuzlalar, mangrovlar, deniz çayırı yatakları, mercanlar, gelgit anında altı metreden derin olmayan deniz kıyısı alanları gibi kıyı sulak alanları, atık su arıtım gölcükleri ve rezervuarlar gibi insan yapımı sulak alanları' kapsamaktadır (Ramsar Sözleşmesi, 1971). Günlük konuşma dilinde bataklık/sazlık olarak tanımlanan su ve sulak alan sistemleri ekolojik özellikleri ve içerdikleri bitki ve hayvan canlı topluluklarından dolayı büyük öneme sahiptiler (Arı 2006). Su ve sulak alan sistemlerinin barındırdıkları biyoçesitlilik, ekosistem servisleri ve üretkenliklerinin devam ettirilebilmesi ancak bütüncül bir yönetim planı sürecinin sürdürülmesine bağlıdır. Ancak, su ve sulak alan sistemlerine ilişkin bütüncül bir planlama ve yönetim uygulaması için öncelikle bu sistemlerinin sahip olduğu fiziksel ve biyolojik dinamiklerin belirlenmesi gerekmektedir. Habitat ve ekosistem çeşitliliği bakımından yüksek zenginliğe sahip olan su ve sulak alan sistemleri, ekonomik ve kültürel bakımdan en çok tercih edilen yaşam ortamlarını oluşturmakta ve toplumların sosyo-ekonomik gelişimlerinde de önemli bir rol oynamaktadır (Atalay 2008). Ancak, nüfus artışına bağlı olarak hızlı ve düzensiz yapılaşma gibi faaliyetler, peyzaj yapısında önemli değişimlere neden olmakta ve bu alanların gün geçtikçe bozulmasına yol açmaktadır (Anonim 2008). Bu kapsamda, kara ve su ile ilişkili habitatları içinde barındıran su ve sulak alan sistemlerinin korunması ve sürdürülebilir yönetimi ise bu alanlarda yürütülecek detaylı envanter çalışmalarına bağlıdır. Bu sulak alan sistemlerinden biri olan Çukurova kıyı peyzajı, Akdeniz havzasında önemli bir biyo-çeşitlilik merkezi olması ve habitat çeşitliliği açısından zengin bir sulak alan potansiyeli barındırması nedeniyle habitat haritalama çalışmalarına konu olmuştur (Yılmaz vd. 2005, Yılmaz vd. 2011).

Bu çalışmada Ege Bölgesi, Aydın ili sınırları içinde bulunan toplam 27.598 ha yüz ölçümüne sahip olan Dilek Yarımadası-Büyük Menderes Deltası Milli Parkı araştırma alanı olarak belirlenmiştir. Seçilen örnek su ve sulak alan sisteminde, içlerinde alanın 
korunmasına yönelik yasal koruma statüleri bulunan (Milli Park ve Tabiat Parkı), barındırdıkları bitki ve hayvan çeşitliliği nedeniyle önemli doğal alanlar arasında yer alan, ve tarihi olarak birbirleriyle fiziksel/ekolojik olarak ilişkili alanlar bulunmaktadır. Bu kapsamda çalışmanın amacl; Aydın ili sınırları içinde yer alan, milli park ve tabiat parkı ile yakın çevresindeki sürekli/geçici sulak alan sisteminin bütüncül planlaması ve yönetiminde altlık oluşturabilecek verilerden biri olan, detaylı bir habitat haritasının oluşturulmasıdır.

\section{Materyal ve Metot}

\section{1 Çalışma Alanı}

Toplamda 55.165 ha'lık bir alana yayılan çalışma alanı, Dilek Yarımadası-Büyük Menderes Deltası Milli Parkı, Bafa Gölü Tabiat Parkı, Azap Gölü ve taşkın alanı, Sarıkemer taşkın alanı ile Büyük Menderes Nehri'nin oluşturduğu su ve sulak alan sistemini kapsamaktadır (Şekil 1). 1966 yılında Milli Park ilan edilen Dilek Yarımadasında, 95 familyaya ait tür, alttür ve varyete düzeyinde 804 takson belirlenmiştir (Durmuşkahya 2000, Aydın Valiliği 2015, Doğa Koruma ve Milli Parklar Genel Müdürlüğü 2018a). Diğer yandan, 1994 yılında Milli Park ilan edilen Büyük Menderes Deltası ise uluslararası öneme sahip 'A Sınıfı Sulak Alan' özelliği taşımaktadır. Dilek Yarımadası ve Büyük Menderes Deltası Milli Parkı içerdiği bu yüksek çeşitlilik nedeniyle Avrupa Konseyi tarafından 'Flora Biogenetik Rezerv Alanı' olarak kabul edilmiştir (Doğa Koruma ve Milli Parklar Genel Müdürlüğü 2018b). Eskiden Ege Denizi'nin bir bölümünü (Latmos Körfezi) oluşturan Bafa Gölü, Büyük Menderes nehri tarafından taşınan alüvyonlarla denizle olan ilişkisi kesilerek, zaman içinde lagün haline dönüşmüştür (Müllenhoff et al. 2004, Brückner et al. 2005 ve 2006, Atak vd. 2012).

Eşbah (2010), günümüzde Bafa Gölü’nü besleyen en önemli su kaynaklarının Büyük Menderes Nehri taşkın suları ve çevredeki dağlardan gelen yeraltı sularının olduğunu ifade etmektedir. Geçmişte bir taşkın ovası özelliği taşıyan Bafa Gölü ve çevresi, günümüzde de Büyük Menderes Deltası'nın sahip olduğu ekosistem özelliklerini taşımaktadır. Bu özelliği ile Bafa Gölü ve çevresi Türkiye'deki 'Önemli Kuş Alanları'ndan (ÖKA) birini oluşturmakta ve dünya ölçeğinde nesli tehlike altında olan birçok kuş türüne üreme ve kışlama ortamı sağlamaktadır (Aydın Valiliği 2015, EKODOSD 2016a).

Söke ilçe sınırları içinde bulunan Azap Gölü ise, Beşparmak Dağlarının eteklerinde, Yağbasan Dağı ile Kırca Tepesi ve Karaburun arasındaki çukur alanda yer almaktadır. Azap Gölü; Avşar, Yeşilköy, Sarıkemer, Özbaşı ve Çalıköy gibi yerleşimlerde bulunan leyleklerin en önemli beslenme alanıdır. Göl yüzeyinde bulunan sazlık ve adacıklarda Fulica atra (sakarmeke), Podiceps cristatus (bahri), Tachybaptus ruficollis (küçük batağan), Anas platyrhynchos (yeşilbaş), Egretta garzetta (küçük akbalıkçıl) ve Tadorna ferruginea (angıt) kuş türlerinin ürediği; Microcarbo pygmeus (küçük karabatak) ve Pelecanus crispus (tepeli pelican) gibi nesli tehlike altında olan türlerin ise kışın gölde barındıkları tespit edilmiştir (Yarar ve Magrin 1997, Aydın Valiliği 2015, EKODOSD 2016b). Azap Gölü, aşağı Büyük Menderes Havzası'nın kuzeyinde kalan Avşar Köyü'nde Büyük Menderes Nehri'nin şiddetli yağmurlar nedeniyle taşmasıyla oluşmaktadır. Özellikle kış aylarında meydana gelen su taşkınları ile oluşan Avşar Gölü birçok canlı türü için zengin bir ekosistem yaratmaktadır. Azap Gölü'nde görülen en önemli kuş türlerinden birini bu bölgeyi barınma alanı olarak seçen leylekler oluşturmaktadır. Ayrıca, yoğun balık popülasyonuna sahip bir sulak alan olması nedeniyle, tepeli pelikanların taşkın dönemlerinde Büyük Menderes Deltası'ndan Azap Gölü'ne beslenme amacıyla geldikleri belirtilmektedir (EKODOSD, 2016c). Ancak, Bafa Gölü Tabiat Parkı başta olmak üzere, seçilen çalışma alanı bütünü, Büyük Menderes Nehri ile taşınan kirlilik ve Bafa Gölü çevresinde yer alan köylerin düzenli çöp depolama alanlarının olmaması nedeniyle hızla kirlenmektedir.

\subsection{Materyal}

Çalışmada, habitat tiplerinin sınırlarının belirlemesi amacı ile $10 \mathrm{~m}$ yersel çözünürlüklü Sentinel-2A uydu görüntüsü temel veri olarak kullanılırken, toprak haritası ve $30 \mathrm{~m}$ yersel çözünürlüklü Aster Global DEM sayısal yükseklik modeli sınıflandırma 
doğruluğunu arttırmak amacıyla ayrı katmanlar olarak kullanılmıştır. Sentinel-2A uydu görüntüleri $60 \mathrm{~m}, 20 \mathrm{~m}$ ve $10 \mathrm{~m}$ yersel çözünürlüğe ve 13 spektral banta sahiptir (ESA 2018). Bu çalışmada, 10m yersel çözünürlüklü ve B02 (mavi-490 nm), B03 (yeşil-560 $\mathrm{nm}$ ) ve B04 (kırmızı-665 nm) bantlardan oluşan gerçek renkli görüntüden (true colour image) yararlanılmıştır.

\subsection{Metot}

Çalışma metodu; seçilen örneklik alanlarda bitki-tür kompozisyonun belirlenmesi amacıyla vejetasyon analizlerinin yürütülmesi ile çalışma alanında nesne tabanlı sınıflandırma yaklaşımı uygulanarak gerçekleştirilen kontrollü sınıflandırmaya dayanmaktadır.

Habitat sınıflandırmasına yardımcı olmak ve doğruluğu arttırmak amacıyla toprak haritasında bulunan toprak özelliklerinden büyük toprak grubu, arazi kullanma kabiliyet sınıfı ve diğer toprak özellikleri sınıflandırmaya dahil edilmiştir. Vektör veri yapısındaki toprak haritasından elde edilen herbir katman $30 \mathrm{~m}$ yersel çözünürlüklü raster veriye dönüştürülerek sınıflandırmaya ayrı ayrı katmanlar olarak katılmıştır. Sayısal yükseklik modeli (Digital Elevation Model-DEM) topoğrafyanın deniz seviyesinden yüksekliğini, coğrafik konumu ile birlikte ifade eden 3 boyutlu bir veri modelidir. Bu çalışmada $30 \mathrm{~m}$ yersel çözünürlüklü ASTER Global DEM sayısal yükseklik modeli verisi en yakın komşuluk (Nearest neighbor) algoritması kullanılarak $10 \mathrm{~m}$ çözünürlükte yeniden örneklendirilerek sınıflandırmaya ayrı bir katman olarak dahil edilmiştir.

Vejetasyon analizlerine dayalı bitki topluluklarının tanımlanması, habitatların sınıflandırılmasında temel veri olarak kullanılmıştır. Vejetasyon ile ilişkili olarak bitki-tür kompozisyonu ile bolluk/örtülülük, bulunma ve dominansi gibi temel vejetasyon parametrelerinden yararlanılmıştır. Bu amaçla 2017 yılında farklı tarihlerde 6 günlük arazi çalışması gerçekleştirilmiştir (11 Mayıs 2017, 08 Haziran 2017, 18 Ekim 2017, 23 Kasım 2017, 24 Kasım 2017 ve 14 Aralık 2017). İlk iki arazi çalışmasında vejetasyon analizleri için toplam 6 örneklik alanda, sonraki dört arazi çalışmasında ise toplam 25 örneklik alanda bitki-tür kompozisyonu kaydedilmiştir. Arazi çalışmalarında kaydedilen bitki taksonlarının topluluk oluşturma açısından özellikleri (bulunma, bolluk-örtülülük, frekans ve konstans değerleri) belirlenmiştir. Çizelge $1^{\prime}$ de bu çalışmalarda kaydedilen bitki taksonları ile bunlara ait bulunma yüzdeleri ve konstans sınıfları sunulmuştur.

Çizelge 1. Vejetasyon analizlerinde kaydedilen bitki taksonları ile bulunma oranları ve konstans sınıfları

\begin{tabular}{|c|c|c|}
\hline Bitki taksonları & Konstans Sınıfları & Bulunma (\%) \\
\hline Asphodellus aestivus & III & 40 \\
\hline Quercus coccifera & III & 40 \\
\hline Arthrocnemum fruticosum & II & 36 \\
\hline Asparagus acutifolius & II & 36 \\
\hline Cistus creticus & II & 32 \\
\hline Tamarix smyrnensis & II & 32 \\
\hline Juncus maritimus & II & 28 \\
\hline Olea europaea var. sylvestris & II & 28 \\
\hline Thymus capitatus & II & 28 \\
\hline Arbutus unedo & II & 24 \\
\hline Calicotome villosa & II & 24 \\
\hline Carthamus dentatus & II & 24 \\
\hline Daphne oleoides & II & 24 \\
\hline Juncus acutus & II & 24 \\
\hline Pistacia lentiscus & II & 24 \\
\hline Sarcopoterium spinosum & II & 24 \\
\hline Spartium junceum & II & 24 \\
\hline Arbutus andrachne & II & 20 \\
\hline Cistus salvifolius & II & 20 \\
\hline Genista acanthoclada & II & 20 \\
\hline Inula chritmoides & II & 20 \\
\hline Pyrus amygdaliformis & II & 20 \\
\hline Salicornia europaea & II & 20 \\
\hline Cistus parviflorus & $\mathrm{I}$ & 16 \\
\hline Hyparrhenia hirta & I & 16 \\
\hline Limonium sp. & I & 16 \\
\hline Smilax aspera & $\mathbf{I}$ & 16 \\
\hline Urgenia maritima & i & 16 \\
\hline Clematis cirrhoza & I & 12 \\
\hline Dactylis glomerata & I & 12 \\
\hline Inula verbascifolia & $\mathbf{I}$ & 12 \\
\hline Juniperus phoenicea & I & 12 \\
\hline Suaeda sp. & I & 12 \\
\hline Aster tripolium & I & 8 \\
\hline Ballota acetabulosa & $\mathbf{I}$ & 8 \\
\hline Bellis perennis & I & 8 \\
\hline Capparis spinosa & $\mathbf{I}$ & 8 \\
\hline Cynanchum acutum & $\mathbf{I}$ & 8 \\
\hline Echinops viscosus & I & 8 \\
\hline Filago sp. & $\mathbf{I}$ & 8 \\
\hline Halimione portulacoides & I & 8 \\
\hline Halocnemum strobilaceum & I & 8 \\
\hline Lavandula cariensis & $\mathbf{I}$ & 8 \\
\hline Paronychia argentea & I & 8 \\
\hline Phragmites communis & $\mathbf{I}$ & 8 \\
\hline Ruscus aculeatus & I & 8 \\
\hline Scrophularia sp. & $\mathbf{I}$ & 8 \\
\hline Teucrium polium & $\mathbf{I}$ & 8 \\
\hline Vulpia sp. & i & 8 \\
\hline Alhagi mannifera & I & 4 \\
\hline Centaurium erytrea & I & 4 \\
\hline Cressa cretica & $\mathbf{I}$ & 4 \\
\hline Helychrisum sp. & i & 4 \\
\hline Hordeum marinum & $\mathbf{I}$ & 4 \\
\hline Hypericum sp. & I & 4 \\
\hline Micromeria myrtifolia & $\mathbf{I}$ & 4 \\
\hline Nerium oleander & $\mathbf{I}$ & 4 \\
\hline Nicotiana glauca & i & 4 \\
\hline Osyris alba & $I$ & 4 \\
\hline Polypogon monspeliensis & i & 4 \\
\hline Rhamnus oleoides & $\mathbf{I}$ & 4 \\
\hline Ulmus minor & $\mathbf{I}$ & 4 \\
\hline
\end{tabular}


Vejetasyon analizi kayıtlarından elde edilen bulgulara göre, çalışma alanında temel habitat tipleri ve bunlar altında yer alan bitki toplulukları tanımlanmıştır.

Habitatların haritalanması: Bu araştırmada uydu görüntüsünün sınıflandırılması ve habitat tipi ayrımlarının yapılması amacıyla nesne tabanlı sınıflandırma yaklaşımı uygulanarak e-Cognition yazılımı Nearest neighbor (en yakın komşu) kontrollü nesne tabanlı sınıflandırma yöntemi kullanılmıştır. Nesne tabanlı sınıflandırma yönteminde görüntüler ölçüt, renk ve şekil gibi özelliklere göre segmentlere ayrılmaktadır (Pillai et al. 2005, Mathieu et al. 2007).

Sınıflandırmada, 7 tane katmandan yararlanılmıştır. Bunlardan 3 tanesi Sentinel-2A uydu görüntüsü bantlarından (Bant 2-mavi, Bant 3-yeşil ve Bant 4kırmızı), 4 tanesi ise yardımcı verilerden oluşmaktadır (yükseklik, büyük toprak grubu, arazi kullanma kabiliyet sınıfı ve diğer toprak özellikleri). Çalışmada kullanılan nesne tabanlı kontrollü sınıflandırmanın uygulaması üç aşamadan oluşmaktadır: (a) segmentasyon aşaması (çokluçözünürlüklü segmentasyon algoritmasımultiresolution segmentation), (b) örnek habitat tiplerinin ve örnek noktaların seçilmesi ve (c) en yakın komşu sınıflandırma yöntemi ile kontrollü sınıflandırmanın gerçekleştirilmesi. Segmentasyon, nesne tabanlı sınıflandırmanın en önemli aşamalarından birisidir. Nesne tabanlı sınıflandırma yönteminde görüntüler ölçüt, renk ve şekil gibi özelliklere göre segmentlere ayrılmaktadır. Görüntüdeki nesnelerin büyüklüğü analizde kullanılan parametrelere göre değişiklik göstermektedir. Görüntünün birbirinden farklı alt bölümlere ayrılması anlamına gelen segmentasyon aşaması ile kullanılan görüntüde istenilen en uygun homojenliği sağlayacak nesne yapısının elde edilmesi amaçlanmaktadır. Bu çalışmada yaygın olarak kullanılan multiresolution segmentation (çoklu-çözünürlüklü segmentasyon) algoritması uygulanmıştır. Çoklu-çözünürlüklü segmentasyon algoritması, ölçek (scale) ve homojenlik (composition of heterogeneity criterion) parametrelerine bağlı olarak çalışmaktadır. Ölçek parametresi, görüntünün mekansal çözünürlüğüne bağlıdır ve nesnenin ortalama büyüklüğü ile ilgilidir.
Bir diğer deyiş ile elde edilecek olan nesnelerin heterojenliğine izin veren maksimum değeri ifade etmektedir. Ölçek parametresi büyüdükçe, elde edilen nesnelerin boyutları da büyümektedir. Homojenlik parametreleri ise, piksellerin birleştirilmesi / gruplanması ile ilgilidir, şekil ve yoğunluk gibi iki ayırt edici özelliği içermektedir. Segmentasyon aşamasında, kullanılan Sentinel-2A uydu görüntüsü bantları ve yardımcı veriler için her bir katman eşit ağırlıklı (1 değeri) olarak değerlendirilmiştir. Birçok deneme sonrasında sınıflandırma için ölçek parametresi olarak 15; şekil ve yoğunluk parametre değerleri ise 0.3 olarak belirlenmiştir. Segmentasyon sonucunda, çalışma alanında toplam 17895 adet segment elde edilmiştir.

Segmentasyondan sonra örnek kontrol alanları belirlenmiştir. Kontrol alanlarının belirlenmesinde; 6 farklı tarihte gerçekleştirilen arazi çalışmalarında elde edilen detaylı notlar, GPS verileri, Google Earth verileri ile vejetasyon analizi değerlendirmeleri temel alınmıştır. İlk adım olarak, çalışma alanında elde edilmek istenilen habitat tipleri arazi çalışmalarından elde edilen bilgiler ve vejetasyon analizi sonuçlarına göre belirlenmiştir. Aynı sınıfa ait nesnelerin alana özgü faktörlere (toprak özelliği, vejetatif kapalılık-açıklık oranı vb. gibi) bağlı olarak ortalama yansıma değerinin farklılık gösterdiği habitat tipleri için, alt habitat sınıfları oluşturulmuş, daha sonra alt habitatlar ana habitat tipi altında birleştirilmiştir. Sınıflandırma sonucunda, bazı alanlarda, nesnelerin spektral ve yersel özelliklerinin benzerlik göstermesi nedeniyle, karışıklığa sebep olan habitat sınıflarına elle düzeltme (manuel editing) işlemi uygulanarak, karışıklığa neden olan habitat tipleri üzerinde düzeltmeler yapılarak sonuç haritasının doğruluğunun arttırılması hedeflenmiştir. Düzeltmelerden sonra elde edilen habitat haritası, shapefile formatında ArcGIS 10.1 ortamına aktarılmıştır. Son olarak, özellikle habitat parçalanmasında önemli etkisi olan yol ve kanallara ilişkin vektör veri elde edilen habitat haritası ile çakıştırılarak haritanın doğruluğunun arttırılması hedeflenmiştir.

Uzaktan algılama yöntemi ile elde edilen görüntü sınıflandırmalarında doğruluk, sınıflandırma sonucu elde edilen habitat sınıflarının yer gerçeği ile 
uygunluğunu ifade etmektedir. Araştırmada, nesne tabanlı kontrollü sınıflandırma sonucunda elde edilen habitat haritasının doğruluk analizi, ArcGIS 10.1 yazılımı yardımı ile örneklere dayalı hata matrisi yöntemi kullanılarak gerçekleştirilmiştir. Doğruluk analizinin gerçekleştirilmesinde kullanılacak olan minimum örnek nokta sayısının belirlenmesinde Snedecor and Cochran (1969)'den yararlanılmıştır ( $N=4 p q$ / E; $N=$ Örneklenecek toplam nokta sayısı, $p=$ beklenilen yüzde doğruluk, $q=100$-beklenilen yüzde doğruluk, $E=$ maksimum izin verilen hata yüzdesi). $\% 85$ doğruluk oranı ve $\% 5$ maksimum hata payı için, minimum örnek nokta sayısı 204 olarak belirlenmiştir. Doğruluk analizi için gerekli olan noktalar ArcGIS yazılımında çok katmanlı rastgele örnekleme noktaları (stratified random sampling) yöntemi kullanılarak oluşturulmuştur. Bu yöntemde noktalarının seçimi, sınıfların arazideki yoğunluğuna ve dağılımına göre belirlenmektedir. Bu aşamada herbir habitat sınıfı için minimum nokta sayısı 10 olmak üzere, toplam örnek nokta sayısı 258 olarak belirlenmiştir. Herbir sınıfın doğruluk değerlendirilmesinin gerçekleştirilmesinde EUNIS (European Nature Information System) habitat haritasI, CORINE (Coordination of Information on the Environment) programı altında geliştirilen CORINE 2012 arazi örtüsü / alan kullanımı haritası, Google Maps ve ArcGIS 10.1 online altlık haritalarının yanı sıra 6 farklı tarihte gerçekleştirilen arazi çalışmalarında elde edilen detaylı notlar ve GPS verilerinden yararlanılmıştır. Doğruluk değerlendirmesinde kullanılan hata matrisi oluşturulmuş, bu temelde elde edilen habitat haritasına ilişkin farklı doğruluk değerlendirmeleri gerçekleştirilmiştir. Bunlar; toplam doğruluk (overall accuracy), üretici doğruluğu (producer's accuracy), kullanıc doğruluğu (user's accuracy) ve kappa istatistik'ten oluşmaktadır. Toplam doğruluk elde edilen sınıflandırma sonucunun, yer gerçeği ile ne kadar uyumlu olduğunu ifade etmekte iken; üretici doğruluğu verilen bir habitat sınıfının örnek alınan noktalar ile ne kadar iyi sınıflandırılabildiğini ve kullanıcı doğruluğu ise kullanıcının yer gerçeğindeki noktalardan ne kadarının sınıflandırılmış harita üzerinde doğru olarak belirlendiğini göstermektedir. Son olarak, kappa (к) katsayısı referans verilerle sınıflandırılmış harita arasındaki gerçek uyumu ve yine referans verilerle rastgele sınıflandırılmış veriler arasındaki şans uyumu arasındaki farkı göstermektedir (Congalton and Gren 2008).

\section{Bulgular}

\subsection{Vejetasyon analizi sonuçları}

Vejetasyon analizi kayıtlarından elde edilen bulgulara göre, ilk aşamada çalışma alanında 6 temel habitat tipi altında yer alan 6 bitki topluluğu tanımlanmıştır. Bu toplulukları temsil eden dominant ve ayırıcı türler Şekil 2'deki dendrogram üzerinde sunulmuştur.

CORINE Habitat Tipleri

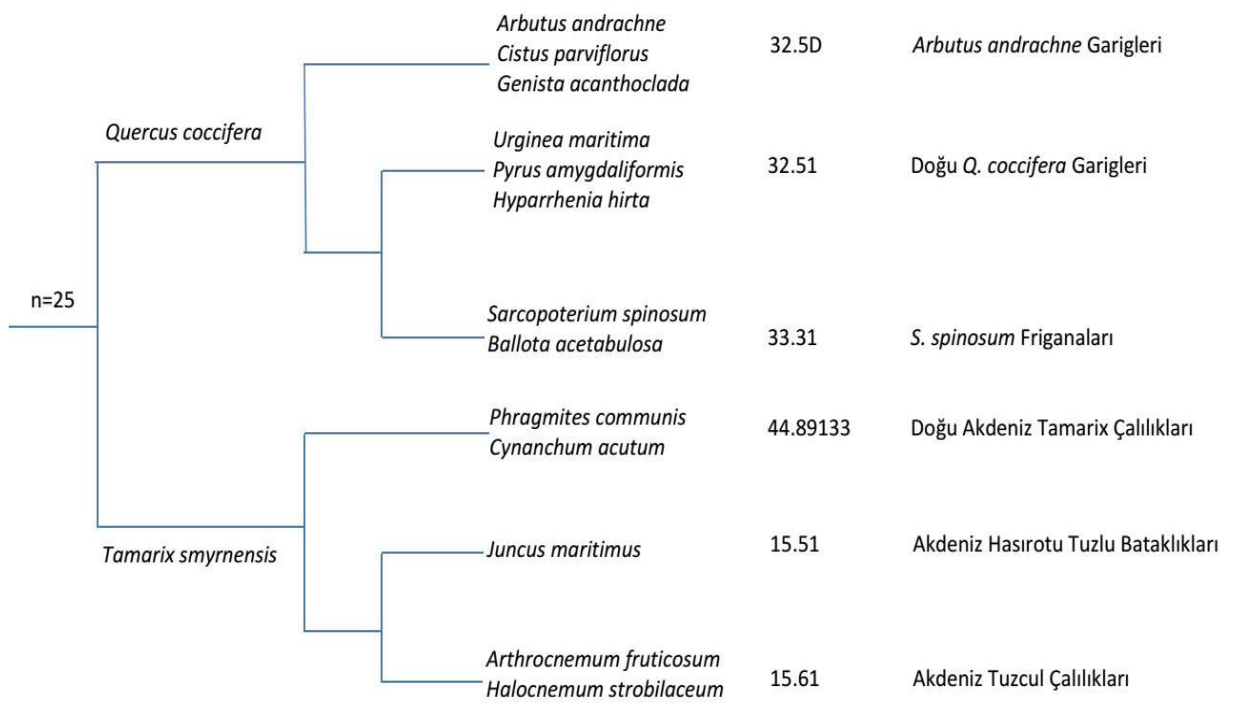

Şekil 2. Vejetasyon analizi verilerine göre çalışma alanında dominant/ayırıcı türlerin ve habitat tiplerinin kümeleme analizi 
Çizelge 2. Vejetasyon analizi verilerine göre çalışma alanında belirlenen CORINE habitat tipleri

\begin{tabular}{ll}
\hline $\begin{array}{l}\text { CORıNE } \\
\text { Habitat Kodu }\end{array}$ & CORıNE Habitat Tipi \\
\hline 11.12 & Kıyı Suları \\
14 & Tuzlu Çamur ve Kum Düzlükleri \\
15.11 & Salicornia europaea Tuzlu Bataklıkları \\
15.51 & Akdeniz Hasırotu Tuzlu Bataklıkları \\
15.61 & Akdeniz Tuzcul Çalılıkları \\
\hline 22 & Durgun Tatlı Sular \\
24 & Akarsular \\
\hline 32.144 & Kızılçam Ağaçsı Matoralleri \\
$32.144(D)$ & Kızıçam Ağaçsı Matoralleri-Degradasyon aşaması \\
$32.5 D$ & Arbutus andrachne Garigleri \\
32.51 & Doğu Quercus coccifera Garigleri \\
33.31 & Sarcopoterium spinosum Friganaları \\
\hline 42.85 & Kızılçam Ormanları \\
44.89133 & Doğu Akdeniz Tamarix Çalılıkları \\
\hline 82.12 & Tarla Tarımı \\
83.1 & BahçeTarımı \\
86 & Yerleşim Alanları, Endüstriyel Alanlar ve Diğer \\
& Yapay Yüzeyler \\
\hline
\end{tabular}

Çalışma alanındaki tüm habitat tiplerinin belirlenmesi ve alt sınıflara ayrılmasında ise, Ekim, Kasım ve Aralık aylarında gerçekleştirilen arazi çalışmalarında elde edilen vejetasyon analizleri, detaylı notlar, fotoğraf ve GPS verileri ile beraber Sentinel-2A uydu görüntüsü ve EUNIS habitat haritasından yararlanılmıştır. Çalışma alanında tespit edilen CORINE habitat tiplerine ilişkin bilgi Çizelge 2'de verilmiştir.

\subsection{Doğruluk analizi sonuçları ve CORINE habitat haritası}

Arazi çalışmalarına dayalı vejetasyon analizi kayıtlarından elde edilen bulgular ışığında eCognition yazılımında nesne tabanlı sınıflandırma yöntemi kullanılarak çalışma alanında toplam 17 adet habitat sınıfı tanımlanmıştır (Şekil 3). ArcGıS 10.1 yazılımı yardımı ile örneklere dayalı hata matrisi yöntemi kullanılarak gerçekleştirilen doğruluk analizi sonucunda, elde edilen habitat haritasının toplam doğruluk oranı \%86.43 (kappa=0.85) olarak saptanmıştır.

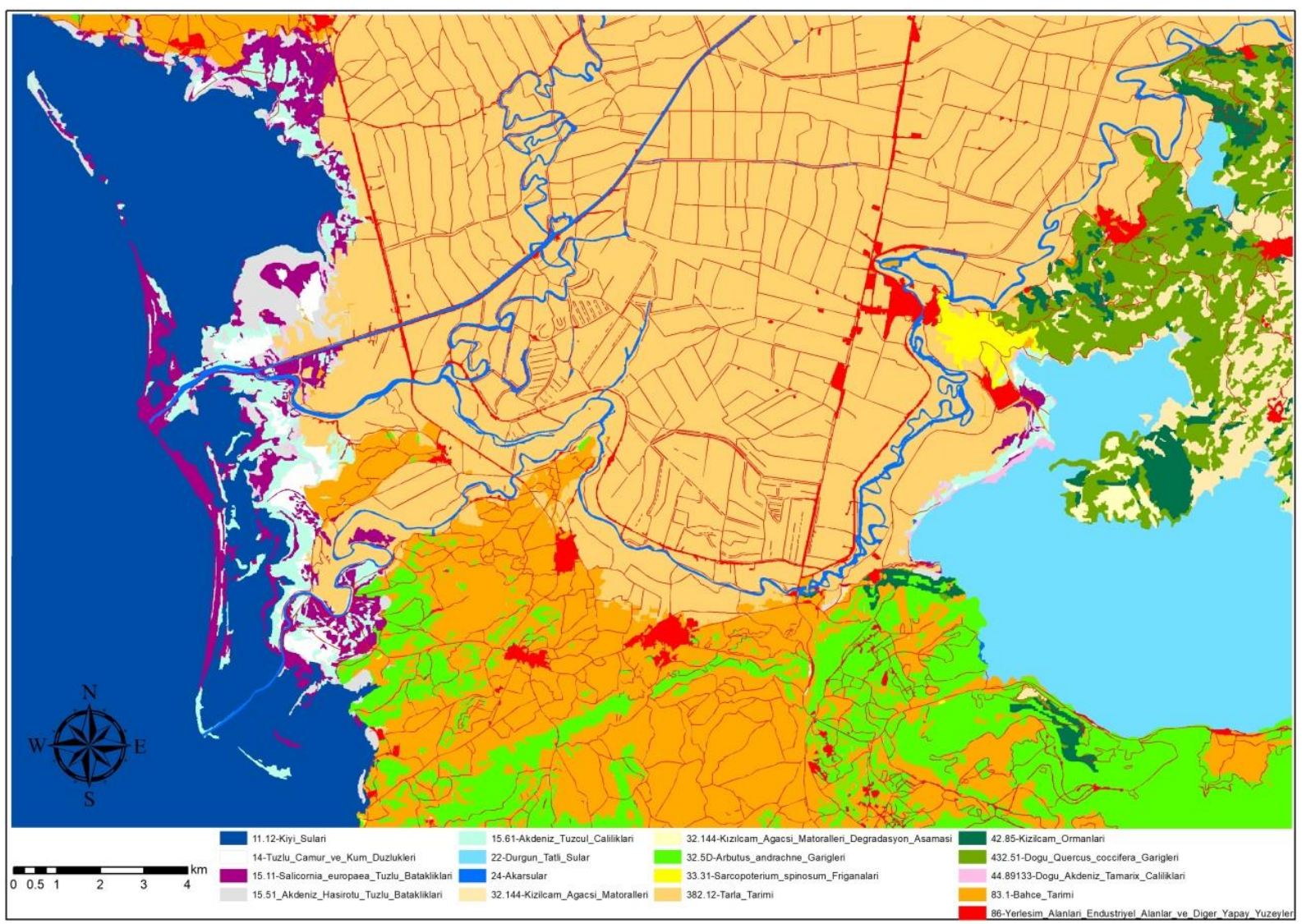

Şekil 3. Çalışma alanında belirlenen CORINE habitat tiplerinin yersel yayılışı . 
Kullanıcı ve üretici doğruluk oranları incelendiğinde, Akdeniz Hasırotu Tuzlu Bataklıkları,

Akdeniz Tuzcul Çalılıkları ile Yerleşim Alanları, Endüstriyel Alanlar ve Diğer Yapay Yüzeyler habitat sınıfları dışında genel olarak her iki doğruluk oranının da \%70 ve üzerinde olduğu görülmektedir. Çalışma alanında hakim habitat tipinin Tarla Tarımı́ndan oluştuğu tespit edilmiştir (\%42.57). Bunu \%13.84, \% 10.57 ve \%8.49 toplam alan ile Bahçe Tarımı, Durgun Tatlı Sular va Arbutus andrachne Garigleri takip etmektedir. Yerleşim Alanları, Endüstriyel Alanlar ve Diğer Yapay Yüzeyler çalışma alanının yalnızca \%5.89'unu kaplamakta iken, diğer habitat tiplerinin çalışma alanındaki alansal oranları ise \%5'in altındadır. Çalışma alanı genelinde, su ve sulak alan sistemlerinin temelini oluşturan ve özellikle su kuşları için önemli habitat alanlarından olan Durgun Tatlı Sular, Akarsular, Kıyı Suları, Tuzlu Çamur ve Kum Düzlükleri, Salicornia europaea Tuzlu Bataklıkları, Akdeniz Hasırotu Tuzlu Bataklıkları ve Akdeniz Tuzcul Çalılıklarının ise çalışma alanı toplamının yaklaşık \%20'sini oluşturduğu belirlenmiştir.

\section{Tartışma ve Sonuç}

Bu çalışmada, 11 Ağustos 2017 tarihli ve $10 \mathrm{~m}$ yersel çözünürlüklü) Sentinel-2A uydu görüntüsü; yükseklik, büyük toprak grubu, arazi kullanma kabiliyet sınıfı ve diğer toprak özellikleri kullanılarak çoklu-çözünürlüklü segmentasyon algoritması yardımıyla nesne tabanlı olarak sınıflandırılmıştır. Sınıflandırma sonucunda çalışma alanında toplam 17 adet habitat sınıfı tanımlanmıştır. Bu çalışmada birçok habitat sınıfı tatmin edici şekilde haritalanabilmesine karşın, Akdeniz Hasırotu Tuzlu Bataklıkları, Akdeniz Tuzcul Çalılıkları ile Yerleşim Alanları, Endüstriyel Alanlar ve Diğer Yapay Yüzeyler habitat sınıflarının haritalanmasında bazı zorluklar yaşanmıştır. Bu nedenle, karışıklığa neden olan bu habitat sınıflarına elle düzeltme işlemi uygulanmış ve sonuç haritasının doğruluğunun arttırılması hedeflenmiştir. Sınıflandırma doğruluğu hata matrisi yöntemi ile test edilmiş ve elde edilen habitat haritasının doğruluğunun \%86.43 (kappa=0.85) olduğu bulunmuştur. Elde edilen doğruluk oranı değerlendirildiğinde; çalışmada uygulanan sınıflandırma yönteminin, arazi çalışmalarına dayalı vejetasyon analizi sonuçları ile birlikte, farklı habitat sınıflarını net bir şekilde ortaya koyduğu görülmüştür.

Bu çalışma ile doğal, kültürel, arkeolojik ve tarihi değerleri açısından büyük öneme sahip olan çalışma alanı örneğinde su ve sulak alan sistemlerinden oluşan peyzajın kapsamlı bir habitat envanteri gerçekleştirilmiş olup, Sentinel-2A gibi $10 \mathrm{~m}$ çözünürlüğe sahip uydu görüntülerinde nesne tabanlı sınıflama metodu kullanarak, uygun segmantasyon parametreleri ile yüksek doğruluk oranına sahip habitat haritalarının oluşturulabileceği sonucuna varılmıştır. Ayrıca, Sentinel-2A gibi yüksek çözünürlüklü uydu görüntülerin yanı sıra, dijital yükseklik modeli ve farklı toprak özelliklerinin sınıflandırma sürecine dahil edilmesi ile yalnızca görüntü bantlarının yansıma değerlerine bağı kalınmadan, peyzajın diğer fiziksel özelliklerinin de dikkate alınabildiği doğruluk oranı yüksek habitat haritalarının elde edilebileceği sonucuna varılmıştır. Bu açıdan, bu çalışmada uygulanan yöntemlerin yalnızca su ve sulak alan sistemlerine ait habitatların değil, başka alanlarda da habitat haritalaması çalışmalarında kullanılabileceği düşünülmektedir.

Insanların yaşamlarını sürdürebilmeleri için gerekli birçok alan/kaynak kullanımlarının çevre üzerindeki etkileri ilk olarak habitatlar düzeyinde saptanabilmektedir (Löfvenhafta et al. 2002). Dolayısıyla, daha öncede bahsedildiği gibi su ve sulak alan sistemlerine ilişkin bütüncül planlama ve yönetim uygulamaları için öncelikle bu sistemlerinin sahip olduğu fiziksel ve biyolojik dinamiklerin habitat haritalama yoluyla belirlenmesi gerekmektedir. Bu kapsamda, koruma temelli planlama ve yönetim uygulamalarında, habitat haritalama çalışmaları, doğa koruma açısından önemli alanların belirlenmesi, bu alanlara ilişkin envanter çıkarılması ve tutarlı bilgi ağlarının oluşturulması ve zaman içinde habitatlarda meydana gelebilecek değişimlerin ve bu değişimleri tetikleyen faktörlerin belirlenmesi bakımından büyük önem taşımaktadır (Yılmaz 1986, Cilliers et al. 2004, Ersoy 2008). Bu çalışmada kullanılan veri ve yöntemlerin, peyzajın bütüncül planlaması ve yönetimine ilişkin çalışmalarda altlık oluşturabilecek 
yüksek doğruluk oranına sahip habitat haritalarının üretilmesinde kullanılabileceği sonucuna varılmıştır. Son olarak, nesne tabanlı sınıflandırma yöntemi ile elde edilen sonuç haritalar vektör yapılı veri olarak Coğrafi Bilgi Sistemi ortamına kolaylıkla entegre edilebilmektedir. Böylece, istenilen çözünürlükte yeniden örneklendirilebilmekte ve diğer analiz uygulamalarına olanak tanıyarak; koruma, yönetim ve iyileştirilme çalışmalarına altık oluşturma açısından da büyük kolaylıklar sağlamaktadır.

\section{Teşekkür}

Bu çalışma, Aydın Adnan Menderes Üniversitesi Bilimsel Araştırma Projeleri (BAP) Birimi tarafından desteklenmiştir. Proje No: ZRF-17044

\section{Kaynaklar}

Anonim, 2008, Semra Kutlubay Planlama Bürosu, AydınMuğla-Denizli 1/100.000 Ölçekli Çevre Düzeni Planı Araştırma Raporu.

Arı, Y., 2006. Ramsar Sözleşmesi'nin Doğa Koruma Yaklaşımına Eleştirel Bir Bakış. Doğu Coğrafya Dergisi, 11 (15), 275-302.

Atak, K.B. Barut, I., Sürücü, A. Z. and Nurlu, E. 2012. Historical Landscape Characterization of Aegean Harbors Since Ancient Time. ECLAS 2012 Conference, The Power of Landscape, September 19-22, 2012, Warsaw University of Life Sciences, Warsaw, POLAND.

Atalay, i., 2008, Ekosistem Ekolojisi ve Coğrafyası, Cilt II, META Basım Matbaacılık Hizmetleri, İzmir. 801.

Brückner, H., Müllenhoff, M., Gehrels, R., Herda, A., Knipping, M. and Vött , A. 2006. From Archipelago to Floodplain-Geographical and Ecological Changes in Miletus and its Environs During the last six Millennia (Western Anatolia, Turkey). Zeitschrift für Geomorphologie, N.F. 142, 63-83.

Brückner, H., Vött, A., Schriever, A. and Handl, M., 2005. Holocene delta progradation in the eastern Mediterranean-case studies in their historical context. Méditerranée. Revue géographique des pays méditerranéens/Journal of Mediterranean geography, 104, 95-106.

Cilliers, S.S., Müller, N. and Drewes, E., 2004. Overview on urban nature conservation: situation in the westerngrassland biome of South Africa. Urban Forestry \& Urban Greening, 3(1), 49-62.
Congalton, R.G. and Green, K., 2008. Assessing the accuracy of remotely sensed data: principles and practices. CRC press. 200.

Durmuşkahya, C., 2000. Dilek Yarımadası- Büyük Menderes Deltası (Kuşadası- Aydın), Biyoçeşitliliği Üzerine Incelemeler, Yüksek Lisans Tezi, Ege Üniversitesi, Fen Bilimleri Enstitüsü, İzmir. 65.

Ersoy, E., 2008. Uydu görüntüsü kullanımıyla Aliağa (İzmir) Kıyı Bölgesi'nde ekolojik açıdan önemli biyotopların haritalanması, Yüksek Lisans Tezi, Ege Üniversitesi, Fen Bilimleri Enstitüsü, İzmir. 112.

Esbah, H., Deniz, B., Kara, B. and Kesgin, B., 2010. Analyzing landscape changes in the Bafa Lake Nature Park of Turkey using remote sensing and landscape structure metrics. Environmental Monitoring and Assessment, 165(1-4), 617-632.

Löfvenhaft, K., Björn, C. and Ihse, M., 2002. Biotope patterns in urban areas: a conceptual model integrating biodiversity issues in spatial planning. Landscape and Urban Planning, 58(2-4), 223-240.

Mathieu, R., Aryal, J. and Chong, A., 2007. Object-based classification of Ikonos imagery for mapping largescale vegetation communities in urban areas. Sensors, 7(11), 2860-2880.

Müllenhoff, M., Handl , M., Knipping , M. and Brückner, H. 2004. The Evolution of Lake Bafa (Western Turkey)-Sedimentological, Microfaunal and Palynological Results. Coastline Reports, 1 (2004) 5566.

Pillai, R.B., Weisberg, P.J. and Lingua, E., 2005, October. Object-oriented classification of repeat aerial photography for quantifying woodland expansion in central Nevada. In 20th Biennial Workshop on Aerial Photography, Videography, and High Resolution Digital Imagery for Resource Assessment, Waslaco, TX, October, 2-6.

Snedecor, G.W. and Cochran, W.C., 1969. Statistical methods 6th ed The lowa State University Press Ames lowa USA.

Yarar M ve Magnin G. 1997. Türkiye'nin Önemli Kuş Alanları. İstanbul: Doğal Hayatı Koruma Derneği.

Yılmaz, K.T., Alphan, H., Berberoğlu,S., İzcankurtaran, Y., 2005. "Bitki Örtüsünün Haritalanmasında Uydu Verilerinin Kullanımı: Çukurova Kıyı Alanı Örneği", Ç.Ü.Z.F. Dergisi, 20 (1),11-20.

Yılmaz, T., 1986, Buca Yerleim Merkezinde Ekoloji Yönünden Önemli Biyotoplar Üzerinde Araştırmalar, Yüksek Lisans Tezi, Ege Üniversitesi, Fen Bilimleri Enstitüsü, Peyzaj Mimarlığı Ana Bilim Dalı, İzmir. 44. 
Yilmaz, Kemal T., Kosztolanyi A., Alphan, H., Akça, E., Çevik, C., Çakan, H., Ünlükaplan, Y. \& Kapur, S., 2011. Short Term Monitoring of Tuz Gölü Lagoon and Adjacent Coastal Habitat Complex for Wetland Management / Mediterranean Coast of Turkey. MEDECOS XII Linking Science to Resource Management, The International Mediterranean Ecosystems Conference. 6-9 September 2011, UCLA, Los Angeles California.

\section{internet kaynakları}

1. https://www.ramsar.org/sites/default/files/doc uments/library/scan_certified_e.pdf,

(19.10.2018)

2. http://webdosya.csb.gov.tr/db/ced/editordosy a/Aydin2015.pdf, (05.06.2017)

3. https://sentinel.esa.int/documents/247904/68 5211/Sentinel-2_User_Handbook, (05.07.2017) http://www.dilekyarimadasi.gov.tr/hakkimizda. asp?id=1, (05.06.2018)

4. http://www.dilekyarimadasi.gov.tr/hakkimizda. asp?id=2, (05.06.2018)

5. https://earthexplorer.usgs.gov/, (13.06.2017)

6. https://earthdata.nasa.gov/, (13.06.2017)

7. http://www.ekodosd.org/index.php/azapgoelue, (10.04.2018)

8. http://www.ekodosd.org/index.php/bafagoelue-tabiat-park, (10.04.2018) 